\title{
DOMINÂNCIA E DEPENDÊNCIA NA CADEIA DE SUPRIMENTOS DE PRIMEIRO NÍVEL: ESTUDO DE CASO DE UM HOTEL DA SERRA GAÚCHA/RS
}

\section{DOMINANCE AND DEPENDENCY ON THE SUPPLY CHAIN OF THE FIRST LEVEL: A CASE STUDY OF A HOTEL IN SERRA GAÚCHA/RS}

\author{
Rodrigo Marques de Almeida Guerra ${ }^{1}$; Maria Salete Goulart Martins Denicol ${ }^{2}$; Guilherme Cunha \\ Malafaia $^{3}$; Vilmar Antônio Gonçalves Tondolo ${ }^{4}$ \\ ${ }^{1}$ Universidade de Caxias do Sul - UCS \\ rmaguerra@ucs.br \\ ${ }^{2}$ Universidade de Caxias do Sul - UCS \\ msdenicol@gmail.com \\ ${ }^{3}$ Universidade de Caxias do Sul - UCS \\ gcmalafa@ucs.br \\ ${ }^{4}$ Universidade de Caxias do Sul - UCS \\ vtondolo@gmail.com
}

\begin{abstract}
Resumo
O presente artigo tem a finalidade de analisar a relação de dominância e dependência exercida em uma cadeia de suprimentos de primeiro nível de um hotel do segmento econômico localizado em Caxias do Sul (RS). A pesquisa pode ser caracterizada como sendo um estudo de caso exploratório qualitativo. Foi realizada entrevista semi-estruturada com o gerente geral da unidade, com a finalidade de obtenção das informações necessárias para a pesquisa. Os elementos analisados foram: relação de dominância e dependência da cadeia de suprimentos de primeiro nível; qualidade da prestação de serviços; nível de essencialidade dos produtos e serviços; e relação de cooperação na cadeia de suprimentos. Os resultados obtidos evidenciaram o grau de dependência do hotel frente aos fornecedores de cinco produtos e serviços, assim como o baixo nível de cooperação existente entre os partícipes do processo (contratos de curto prazo baseados muito mais na sobrevivência de suas operações do que na obtenção de retorno financeiro a longo prazo.
\end{abstract}

Palavras-chave: cadeia de suprimentos; dominância e dependência; serra gaúcha.

\section{Introdução}

A cadeia de suprimentos, em sua grande maioria, apresenta conceitos oriundos do Sistema Toyota de Produção (STP). A influência exercida pelas operações industriais deve-se ao fato da adaptação das estratégias de produção às operações logísticas, bem como a ausência de conceitos próprios desenvolvidos para a área de serviços. Desta forma, o surgimento de conceitos relacionados aos serviços logísticos, realizados dentro da cadeia de suprimentos, foi influenciado pelas operações industriais, mais precisamente, pelo STP (COX, 1999). 
O serviço logístico básico é medido em termos de disponibilidade, desempenho operacional e confiabilidade de serviço. A disponibilidade está relacionada com o estoque para atender de forma consistente às necessidades de materiais e/ou produtos para o cliente. O desempenho operacional diz respeito ao tempo decorrido, desde o momento do recebimento do pedido, até a entrega da mercadoria. A confiabilidade do serviço está ligada ao atributo de qualidade logística, tornando-se essencial adotar medidas para avaliar a disponibilidade de estoque e o desempenho operacional (BOWERSOX; CLOSS, 2001).

A busca de novos parâmetros para mensuração do desempenho das operações da cadeia de suprimentos, relacionadas às atividades de serviços, é justificada pela necessidade de diferenciação frente às cadeias concorrentes. Portanto, percebe-se a preocupação em analisar as operações como um todo, inclusive as de serviços.

A gestão da cadeia de suprimentos envolve mudanças significativas nas tradicionais relações entre comprador e fornecedor existindo uma tendência de redução do número de fornecedores estratégicos no intuito de melhor atendimento e qualidade na prestação de serviços, passando a existir uma relação de parceria entre fornecedores e empresas (CAVALLARI; SCHWABE; MACHADO, 2002). Desta forma, o foco da gestão da cadeia de suprimentos está na cooperação, na confiança e no reconhecimento de que bem gerido, o "todo pode ser maior que a soma de suas partes" (CHRISTOPHER, 2012).

O objetivo deste artigo é analisar a dominância e dependência dentro da cadeia de suprimentos de primeiro nível, de um hotel localizado na Serra Gaúcha, a partir das relações de compra e fornecimento de cinco principais produtos e serviços.

Além da parte introdutória, o artigo apresenta mais quatro seções. A segunda seção apresenta a construção da fundamentação teórica. A terceira seção descreve o procedimento metodológico utilizado para elaboração do trabalho. A quarta seção aborda o estudo de caso desenvolvido em um hotel localizado na Serra Gaúcha/RS. Já quinta e última seção apresentam as considerações finais oriundas do estudo realizado.

\section{Fundamentação teórica}

\subsection{Cadeia de suprimentos}

A cadeia de suprimentos pode ser conceituada como sendo uma rede de organizações interligadas em duplo sentido, desde o fornecedor até o cliente, tendo a finalidade de atender a exata necessidade dos consumidores finais. Este arranjo de empresas desenvolve produtos e/ou serviços a um baixo custo, de forma ágil, de acordo com a demanda dos clientes, a um preço justo, devendo ser entregues dentro do prazo estabelecido (BOWERSOX et al, 2003). 
Para que o propósito da cadeia de suprimentos seja atingido, esta associação de empresas deve realizar o controle de seus processos de forma cooperativa, coordenada e participativa de todos os elementos formadores da cadeia. A visão compartilhada de suas atividades permitirá um ótimo gerenciamento e controle dos fluxos de materiais/insumos, pessoas, informações, produtos e dinheiro (CHOPRA; MEINTL, 2001; BOWERSOX; CLOSS, 2001).

A cadeia de suprimentos é um conjunto de organizações que possuem relações a jusante e/ou a montante em relação à empresa focal. A gestão da cadeia de suprimentos deve permitir a obtenção de valor superior, ao menor custo possível, para os elementos integrantes visando à competitividade (CHRISTOPHER, 2012).

O objetivo da cadeia de suprimentos é desenvolver parcerias com a finalidade de obtenção de competitividade da cadeia de suprimentos frente às cadeias concorrentes. Portanto, competitividade organizacional não existe apenas na firma, mas sim entre cadeias de suprimentos (CHOPRA; MEINTL, 2001). A Figura 1 ilustra uma representação esquemática de uma cadeia de suprimentos genérica.

Figura 1 - Representação de uma cadeia de suprimentos

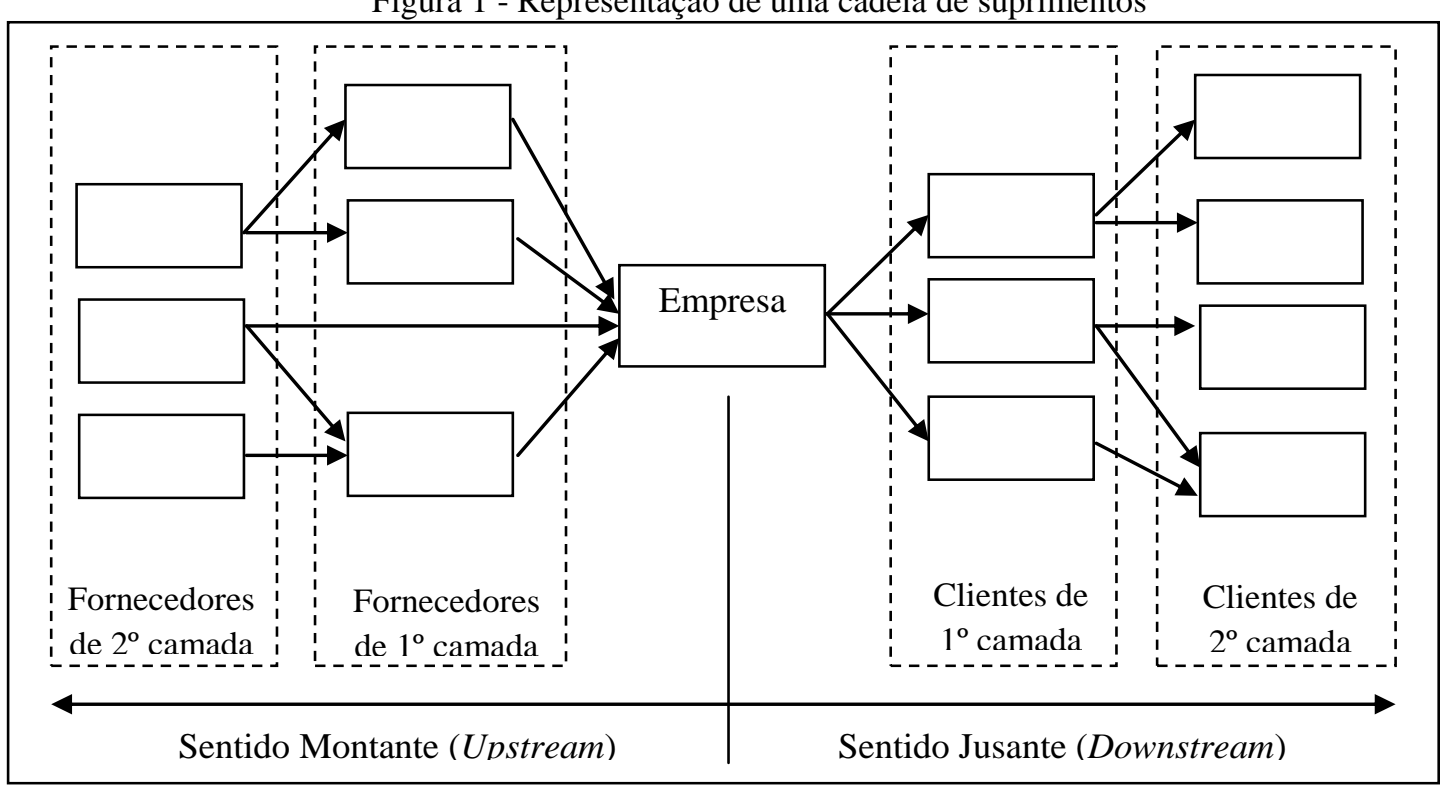

Fonte: Adaptado de Lambert et al (1996)

Devido à necessidade da concorrência entre cadeias de suprimentos, as empresas precisam surgir "enxutas" o suficiente para realizarem suas operações de forma eficiente tanto a montante do processo como a jusante (Figura 1). Dependendo da complexidade da cadeia de suprimentos, a mesma pode possuir diversas camadas (número de empresas que estabelecem relações com a empresa focal de forma direta ou indireta) (LAMBERT et al, 1996).

Desta forma, quanto maior for à rede (teia) da cadeia de suprimentos, maior será o número de camadas e, consequentemente, a complexidade de suas relações (de poder, dependência, dominância, conflito, parcerias, performance etc.) (COX; SANDERSON; WATSON; 2001). 


\subsection{Relacionamento na cadeia de suprimentos}

Se o relacionamento na cadeia de suprimentos existirem com base no compartilhamento de informações, planejamento conjunto, resolução de problemas, medidas de performance e alavancagem (MIN et al, 2001), a relação estabelecida na cadeia é de ganho mútuo entre seus elementos (BOWERSOX et al, 2003).

Entretanto, as relações de aliança estabelecidas entre os partícipes de uma cadeia de suprimentos visam o sacrifício "para manter o relacionamento e para fazê-lo crescer". Isto significa a renuncia de ganhos (em curto prazo) em troca de retornos futuros, tendo em vista as oportunidades existentes com a aliança, que, muitas vezes, não ocorre (COUGHLAN et al, 2002; COX; SANDERSON; WATSON; 2001).

O relacionamento na cadeia de suprimentos tem sido alvo de críticas por parte de alguns autores. Os mesmos afirmam que esta integração é desenvolvida apenas a partir da necessidade de relações comerciais, sendo apenas acordos de conveniência, não visando, portanto, a cooperação. A análise da relação "ganha a ganha", formada pela teoria, não passa de mera disputa de poder, na prática (COUGHLAN et al, 2002; BARRATT, 2004).

A visão de Cox (2004) é mais moderada. O mesmo afirma que o estabelecimento de cooperação pode estar presente em uma determinada cadeia, porém, em outra pode não existir. Mesmo assim, há relação de cooperação entre os elementos da cadeia, contudo em um nível de dominância e dependência (existência de poder).

\subsection{Tipos de relacionamentos na cadeia de suprimentos}

O grau de relacionamento existente na cadeia de suprimentos vai depender da relação (nível) de cooperação existente entre as empresas participantes da cadeia (formação de poder na cadeia) (CHOPRA; MEINTL, 2001; COUGHLAN et al, 2002).

Poder pode ser definido de diversas formas, sendo considerado equivalente ao grau de liderança, influência, coerção, autoridade e parceria estabelecida entre os elementos de uma cadeia. Portanto, o nível de eficiência das operações realizadas pelos elementos da cadeia depende da governança e resolução de conflitos. Quanto mais complexa for à cadeia, maior deve ser o grau de intervenção do elemento de maior poder (dominância) sobre o elemento dependente (COX; SANDERSON; WATSON, 2001).

Dominância pode ser conceituada como sendo a aceitação, por parte do elemento dependente, de realizar atividades determinadas pelo elemento de maior influência (ou poder) dentro da cadeia (COX, 1999). Esta "imposição" pode estar relacionada à sobrevivência de uma empresa, pelo fato de possuir apenas um fornecedor de produto e/ou serviço, por exemplo. Já a autoridade, exige grau de convencimento (persuasão) sobre determinada empresa. 
Cox, Sanderson e Watson (2001) estabelecem algumas relações de dominância (e dependência) na cadeia de suprimentos, a saber:

- Dominância exercida pelo comprador: (1) poucos compradores e muitos fornecedores; (2) dependência dos fornecedores; (3) produtos comercializados são commodities; (4) relação com o comprador representa alta porcentagem das transações do fornecedor; e (5) custo de troca de fornecedores é baixo.

- Interdependência: (1) poucos compradores e fornecedores; (2) dependência dos fornecedores; (3) não há commodities; (4) poucas opções de fornecedores; (5) relação com o comprador representa alta porcentagem das transações do fornecedor; e (6) custo de troca de fornecedores é alto.

- Independência: (1) muitos compradores e fornecedores; (2) produtos comercializados são commodities; (3) relação com o comprador não representa alta porcentagem das transações do fornecedor; e (4) custo de troca de fornecedores é baixo.

- Dominância exercida pelo fornecedor: (1) muitos compradores e poucos fornecedores; (2) não há dependência dos fornecedores; (3) não há commodities; (4) poucas opções de fornecedores; (5) relação com o comprador representa baixa porcentagem das transações do fornecedor; e (6) custo de troca de fornecedores é alto.

Alguns estudos evidenciam a dependência da prestação de serviços logísticos na cadeia de suprimentos (SVENSSON, 2003; MCIVOR, 2003; FABBE-COSTES; JAHRE; ROUSSAT, 2009), relacionando a eficiência das operações de serviços logísticos com a formação de parcerias estratégicas entre cliente-fornecedor, com o intuito de melhorar o nível do serviço, reduzir custos e minimizar o tempo da prestação do serviço.

A terceirização da prestação de serviços pode ser definida como sendo a aquisição de um bem ou serviço a partir de uma terceira pessoa ou parte interessada (GILLEY; RASHEED, 2000). Sendo assim, analisar o relacionamento comprador-fornecedor é importante para a formulação de estratégias para a organização (HARLAND et al, 2005). Um dos fatores que influencia as organizações a contratarem serviços terceirizados é o custo de transação da operação (VIVALDINI; PIRES, 2011). Sendo assim, o custo de transação passa a interferiri diretamente na determinação das estratégias de negócio da empresa (LONSDALE, 2001).

Outro fato que influencia a relação de dominância de dependência na cadeia de suprimentos é o nível de interdependência da prestação de serviço, ou seja, a frequência ciclica ou não-ciclica da contratação do produto e/ou serviço.

Assim, o alto nível de interdependência indica uma forte relação de cooperação entre as empresas (alto investimento, confiança, compromisso mútuo etc.) (CASCIARO; PISKORSKI, 
2005). Portanto, quanto maior for o nível de dependência maior será o grau de interação econômica entre os parceiros de troca, o que fortalece a troca relacional entre as partes (GULATI; SYTCH, 2007).

\section{Procedimento metodológico}

O presente estudo pode ser caracterizado como sendo exploratório qualitativo. A pesquisa exploratória tem o propósito de se aprofundar no assunto estudado, tendo em vista familiaridade do pesquisador sobre o objeto investigado (LAKATOS; MARCONI, 2011).

Foi realizado um estudo de caso com o propósito de conhecer determinadas situações, servindo, portanto, como instrumento de investigação e aprofundamento da vida real do indivíduo ou grupos sociais. O estudo empírico investiga um fenômeno atual num ambiente não claramente definido (EISENHARDT, 2010; YIN, 2010). A amostra escolhida foi não probabilística do tipo por conveniência, devido à facilidade de acesso ao entrevistado pelos pesquisadores (MALHOTRA, 2011). O nome da empresa investigada não será revelado por motivos estratégicos.

O instrumento de coleta de dados predominantemente utilizado para realização da pesquisa foi um roteiro de entrevista semi-estruturado. Foi solicitado, também, que o entrevistado preenchesse quatro quadros, por meio da escala de Likert de cinco pontos, indicando quais seriam os aspectos intangíveis da qualidade dos serviços aos clientes, a relação de dominância e dependência dos produtos e serviços analisados e os fatores que possuem maior influência no relacionamento da cadeia de suprimentos de primeiro nível.

A entrevista foi realizada com o gerente geral do hotel, no intuito de compreender a relação de dominância e dependência na cadeia de suprimentos da empresa. Para isto, foi necessário aplicar um roteiro de entrevista composta por 10 questões semi-estruturadas (pesquisa qualitativa). O tempo médio das entrevistas foi de uma hora e vinte minutos, tendo sido realizada nas dependências do hotel.

As entrevistas foram gravadas e, posteriormente, transcritas, visando melhor entendimento e elaboração do estudo de caso. Foi utilizada a análise de conteúdo (BARDIN, 1979), para o tratamento das questões subjetivas, com base nas seguintes técnicas: análise categorial, análise de avaliação, análise da enunciação, análise da expressão, análise das relações e análise do discurso. Para este trabalho, a técnica utilizada nas entrevistas foi a análise do discurso dos entrevistados.

\section{Estudo de caso de um hotel da serra gaúcha/RS}

\subsection{Descrição da empresa pesquisada}


A empresa investigada foi um hotel localizado na cidade de Caxias do Sul (RS) do segmento econômico. O hotel possui 1500 unidades espalhadas pelo mundo. Na América Latina apresenta 100 instalações, sendo 12 localizadas no estado do Rio Grande do Sul.

A unidade de Caxias do Sul já está em funcionamento há nove anos, possui 140 apartamentos e apresenta um faturamento médio anual de 4,9 milhões. A taxa média de ocupação no período de alta estação é de $70 \%$ e de $60 \%$ no período de baixa demanda. A unidade investigada possui 34 funcionários.

De acordo com a pesquisa realizada com o gerente geral da unidade, o mesmo afirma que: “É a maior taxa de ocupação de todos os hotéis da cidade". Este fato demonstra a grande demanda apresentada pela rede hoteleira no segmento econômico, estando direcionada para executivos e clientes que realizam negócios na cidade.

\subsection{Grau de importância da qualidade dos serviços aos clientes}

Quanto ao grau de importância relativo à qualidade dos serviços oferecidos aos clientes, constatou-se que os itens mais importantes (peso 5) foram assinalados para os atributos: acesso, atendimento, comunicação e limpeza/higiene. Já os atributos velocidade, competência, custo, conforto e estética (aparência) forma assinalados com peso 4. Os elementos segurança e flexibilidade apresentaram, respectivamente, pesos 3 e 2 (Quadro 1).

\begin{tabular}{|c|c|c|c|c|c|}
\hline \multirow{2}{*}{$\begin{array}{l}\text { Aspectos intangíveis da } \\
\text { qualidade dos serviços } \\
\text { aos clientes }\end{array}$} & \multicolumn{5}{|c|}{$\begin{array}{c}\text { Grau de importância da qualidade dos serviços } \\
\text { oferecidos aos clientes }\end{array}$} \\
\hline & 1 & 2 & 3 & 4 & 5 \\
\hline Acesso & & & & & $\mathrm{X}$ \\
\hline Velocidade & & & & $\mathrm{X}$ & \\
\hline Competência & & & & $\mathrm{X}$ & \\
\hline Atendimento & & & & & $\mathrm{X}$ \\
\hline Flexibilidade & & $\mathrm{X}$ & & & \\
\hline Segurança & & & $X$ & & \\
\hline Custo & & & & $\mathrm{X}$ & \\
\hline Comunicação & & & & & $\mathrm{X}$ \\
\hline Limpeza/higiene & & & & & $\mathrm{X}$ \\
\hline Conforto & & & & $\mathrm{X}$ & \\
\hline Estética (aparência) & & & & $\mathrm{X}$ & \\
\hline
\end{tabular}

Fonte: Pesquisa de campo (2012)

Por meio da pesquisa, pode-se perceber que o item "acesso" obteve peso 5 devido a preocupação da empresa em possuir (três) apartamentos adaptados a portadores de necessidades especiais, todos localizados no primeiro andar do hotel.

O gerente geral do hotel afirmou que: "todos os três apartamento que temos no hotel são totalmente adaptados [aos portadores de necessidades especiais]. Isto permite a inclusão de clientes e o compromisso da empresa em recebê-los de forma apropriada". 
Outro aspecto destacado durante a pesquisa diz respeito ao fácil acesso que o hotel tem em relação a seus concorrentes. "Nossa localização é privilegiada em relação aos nossos concorrentes. Estamos situados na entrada da cidade, o que permite fácil identificação dos clientes”, afirmou o entrevistado.

Com relação ao aspecto "competência", a empresa informou que existe grande dificuldade quanto ao preenchimento de vagas direcionada para o segmento da empresa (setor hoteleiro), pelo fato da cidade de Caxias do Sul possuir característica predominantemente industrial, o que acarreta a especialização da mão-de-obra neste setor e não relacionado ao de turismo.

Outro aspecto importante que deve ser destacado diz respeito ao elemento "atendimento", que apresentou peso 5 na pesquisa. O entrevistado afirmou que: "A unidade de Caxias do Sul apresenta um excelente atendimento aos clientes. Fomos primeiro lugar na pesquisa realizada, pela rede do hotel, no ano 2010 e 2011, no quesito atendimento ao cliente. Estamos em quinto lugar nesta mesma pesquisa, até o momento, neste ano [2012]. Isto prova nosso grau de excelência e prioridade no atendimento ao cliente".

A flexibilidade das operações apresentou peso 2 pelo fato do hotel ser uma rede de franquias, desta forma não apresenta um processo flexível, mas sim "rígido" com relação a tomada de decisão". O item "segurança" foi considerado neutro (peso 3) pelo fato da inexistência de ocorrência de assaltos ou furtos no hotel. "Estamos posicionados em frente a uma concessionária de veículos que possui vigilância 24 horas. Nos sentimos mais seguros, porém não podemos descuidar. Temos uma equipe de vigilância terceirizada das 19 às 7 horas".

Os elementos "custo" e "estética (aparência)" foram considerados peso 4 pelo fato do hotel ser direcionado para o público econômico e executivo. Outra justificativa diz respeito ao baixo custo da instalação física do hotel. "Qualquer unidade da rede é construída com recursos de investidores, chamado de "pull" de investidores. Eles ganham um aluguel [como qualquer outro imóvel para investimento], que é pago de acordo com a taxa de ocupação do hotel por mês. Precisamos reformar os apartamentos. Este é um compromisso assumido pelo hotel, pois fomos uma franquia. Não importa em que hotel da rede esteja hospedado. O serviço precisa ser padronizado", afirma o entrevistado.

Os itens "limpeza/higiene" e "comunicação" foram assinalados com peso 5 (maior grau de importância). "Somos uma franquia. Precisamos ter uma comunicação padronizada e direcionada para nosso público [alvo]. A agilidade precisa existir, porém sem interferir [negativamente] na qualidade da prestação [do serviço]. Quanto ao item "limpeza/higiene", é uma das principais preocupações. Não podemos ter reclamações, pois poderá repercutir na baixa demanda [do hotel]. A limpeza é o nosso maior ponto forte, juntamente com o item atendimento". 


\subsection{Dominância e dependência na cadeia de suprimentos}

\subsubsection{Fornecedores de produtos de $1^{\circ}$ nível}

Em relação à dominância e dependência existente entre os fornecedores de primeiro nível da cadeia de suprimentos da empresa, verificou-se que os principais fornecedores de produtos para o hotel foram, a saber: padaria (peso 1), produtos de limpeza/higiene (peso 2), hortifrutigranjeiros (peso 1), vinícolas (peso 4) e impressos (peso 4), conforme Quadro 2.

O peso 5 representa maior grau de dominância; já o peso 3, apresenta neutralidade quanto ao grau de dominância e dependência; o peso 1, diz respeito ao maior grau de dependência da empresa frente aos principais fornecedores de primeiro nível da cadeia.

\begin{tabular}{|c|c|c|c|c|c|}
\hline \multirow{2}{*}{$\begin{array}{l}\text { Cinco principais fornecedores de } \\
\text { PRODUTOS }\end{array}$} & \multicolumn{5}{|c|}{ Escala (dominância e dependência) } \\
\hline & 1 & 2 & 3 & 4 & 5 \\
\hline 1. Padaria & $\mathrm{X}$ & & & & \\
\hline 2. Produtos de limpeza/higiene & & $\mathrm{X}$ & & & \\
\hline 3. Hortifrutigranjeiro & $\mathrm{X}$ & & & & \\
\hline 4. Vinícolas & & & & $\mathrm{X}$ & \\
\hline 5. Impressos & & & & $\mathrm{X}$ & \\
\hline
\end{tabular}

Fonte: Pesquisa de campo (2012)

A representação esquemática dos principais fornecedores de produtos de primeiro nível da cadeia de suprimentos do hotel investigado pode ser visualizada na Figura 2.

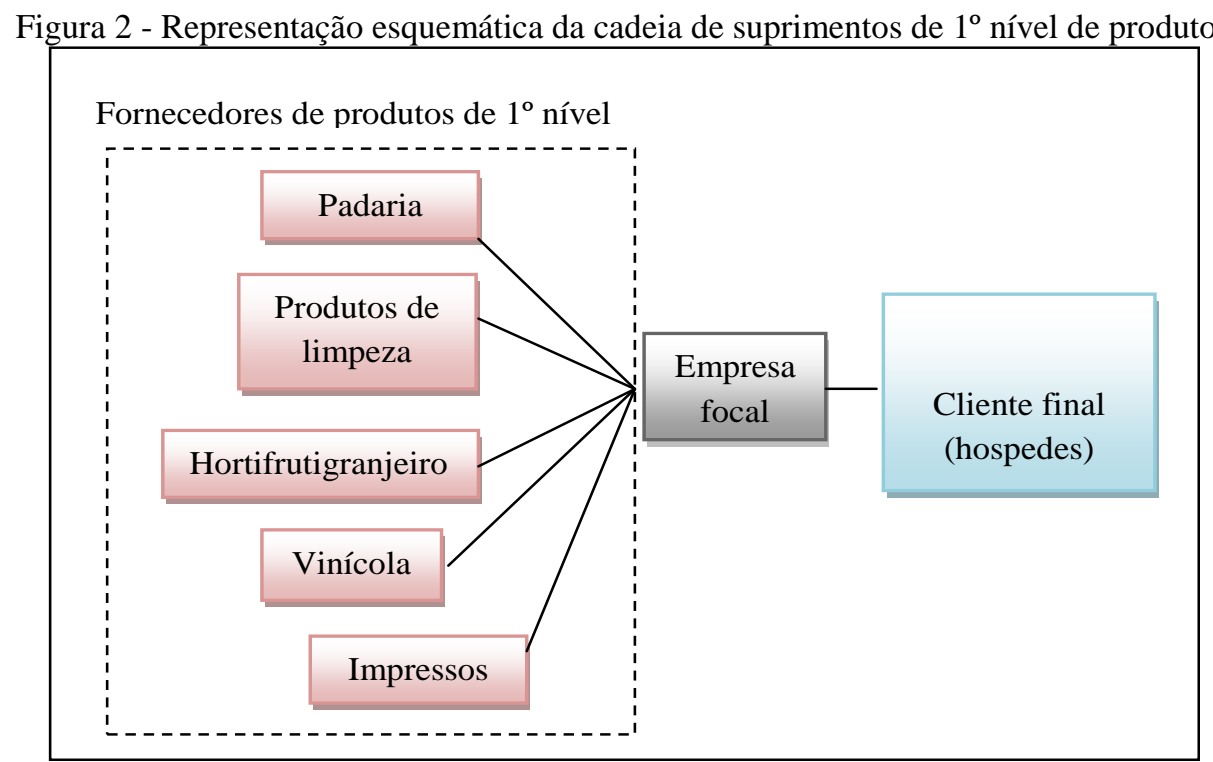

Fonte: Autoria própria (2012)

Os elementos identificados na pesquisa para determinação da relação de dominância e dependência dos fornecedores do primeiro nível da cadeia de suprimentos, bem como a pontuação (peso) para cada item, respeitaram os seguintes critérios: padaria e hortifrutigranjeiros (peso 1 mais dependente), produtos de limpeza/higiene (peso 2); vinícolas e impressos (peso 4); nenhuma opção foi escolhida, pela empresa, como peso 3 (neutro) e 5 (mais dominante). 
O item "padaria" foi avaliado com peso 1 (mais dependência), pelo fato de apenas uma padaria da cidade ter condições de atender a demanda do hotel dentro do prazo estabelecido (6 horas da amanhã) e com qualidade do produto. Outro aspecto avaliado diz respeito ao atendimento da demanda em períodos de sazonalidade (ajuste ao aumento do fluxo de hospedes no hotel).

Desta forma, pode-se perceber que existe um alto grau de dependência do hotel em relação ao fornecimento de produtos como pães, biscoitos, salgados, tortas, bolos ou qualquer outro oferecido pela padaria para o café da amanhã dos hospedes.

O elemento "produtos de limpeza/higiene" foi julgado com peso 2. O aspecto mais relevante para a escolha foi o fato da necessidade da empresa adquirir produtos de boa qualidade a um preço competitivo no mercado. Percebeu-se que a empresa necessita comprar grande quantidade de produtos para a atividade de limpeza/higiene, todavia não é um critério para poder de barganha.

O entrevistado afirmou que: “A rede de hotéis tem a possibilidade de contratar apenas 2 ou 3 fornecedores [estabelecida pela unidade central da rede localizada na cidade de São Paulo]. A lista fica no sistema da empresa, que possui liberdade de escolha. Pelo fato da empresa comprar diretamente do fabricante, não conseguimos ter alto grau de barganha na relação comercial”.

Pode-se perceber, portanto, que há dependência do hotel em relação ao fabricante de produtos de limpeza. Não existe tanto grau de liberdade de escolha (poder de decisão), pelo fato da existência de poucos fornecedores que atendam a alta demanda dos hotéis, dentro da quantidade, prazo e custo estabelecido no contrato.

O item "hortifrutigranjeiro" apresentou um alto grau de dependência do hotel em relação ao fornecedor de produtos (Ceasa da cidade de Caxias do Sul). O grau de prioridade para a escolha do fornecedor está na localização (proximidade deste em relação ao hotel) e a qualidade dos produtos (serem novos e de boa aparência).

Já para o elemento "vinícolas", o hotel apresenta grau de dominância (peso 4), devido ao alto número de empresas existentes nas cidades que fazem parte da Serra Gaúcha (Caxias do Sul, Farroupilha, Bento Gonçalves, Garibaldi, Carlos Barbosa etc.). Existe grande oferta por parte das vinícolas em expor seus produtos no hotel. Este fato permite a empresa analisada diversificar a escolha de fornecedores para os produtos do gênero (vinhos, sucos de uva, geléias, cremes e hidratantes a base de uva etc.). Atualmente, existem oito vinícolas que expõem seus produtos, para comercialização, no hotel.

Os "impressos" apresentam um alto grau de dominância identificado pelo hotel. Devido à elevada quantidade de produtos para impressão (publicidade e propaganda, por exemplo), interesse das empresas deste setor em ter o hotel como cliente, alto número de empresa deste segmento (grande quantidade de empresas industriais, comerciais e de serviços que realizam impressões em grande escala e com necessidade de qualidade do produto) localizada na cidade de Caxias do Sul. 
Outro fator importante é o tempo de resposta que o hotel precisa ter para a obtenção dos impressos. Muitas empresas não conseguem atender a alta demanda, devido ao elevado número de trabalho que já possui dentro do prazo estabelecido no contrato (geralmente dentro do período de um ano - curto prazo).

\subsubsection{Prestadores de serviços de $1^{\circ}$ nível}

A representação esquemática dos principais fornecedores de serviços de primeiro nível da cadeia de suprimentos do hotel investigado pode ser visualizada na Figura 3.

Com relação aos cinco principais prestadores de serviços obtidos pelo hotel, este analisou o grau de dominância e dependência da seguinte forma: lavanderia (peso 1), internet (peso 2), telefonia (peso 2), manutenção para ar condicionados (peso 2) e manutenção para elevadores (peso 3). A escala de dominância e dependência atribuiu ao peso 1 maior grau de dependência e ao peso 5 maior grau de dominância.

O elemento "lavanderia" foi julgado com peso 1 (maior grau de dependência). A prestação do serviço é terceirizada e já foi mudado devido a não adaptação da empresa à demanda da empresa.

Quadro 3 - Grau de dominância e dependência dos cinco principais prestadores de serviços

\begin{tabular}{|c|c|c|c|c|c|}
\hline \multirow{2}{*}{$\begin{array}{c}\text { Cinco principais prestadores de } \\
\text { SERVIÇOS }\end{array}$} & \multicolumn{5}{|c|}{ Escala (dominância e dependência) } \\
\cline { 2 - 6 } & $\mathbf{1}$ & $\mathbf{2}$ & $\mathbf{3}$ & $\mathbf{4}$ & $\mathbf{5}$ \\
\hline 1. Lavanderia & $\mathrm{X}$ & & & & \\
\hline 2. Internet & & $\mathrm{X}$ & & & \\
\hline 3. Telefonia & & $\mathrm{X}$ & & & \\
\hline 4. Manutenção (ar condicionado) & & $\mathrm{X}$ & & & \\
\hline 5. Manutenção (elevadores) & & & $\mathrm{X}$ & & \\
\hline
\end{tabular}

Fonte: Pesquisa de campo (2012)

O entrevistado afirmou que: "Já realizamos mudança quanto ao prestador de serviço da lavanderia. Eles nos atenderam muito bem nos dois primeiros anos do contrato, mas depois deixaram a qualidade do serviço cai. [A lavanderia] É um serviço que cuida diretamente de nosso enxoval, que é essencial para nossos apartamentos. Não podemos perder qualidade ou não termos esse itens [enxoval] num período de alta demanda".

O item "internet" foi avaliado com peso 02 pelo hotel. "Todos os serviços [de internet] da rede são realizados pela Embratel. Não existe outra possibilidade", afirmou o gerente geral da unidade de Caxias do Sul. Pode-se afirmar, portanto, que existe uma centralização da tomada de decisão que interfere diretamente na dependência do serviço. "A internet é um serviço essencial para nossas operações, assim como para os clientes. Nosso perfil de cliente é bastante exigente para este serviço. Não podemos ficar sem [internet]", completa o entrevistado.

O item "telefonia" (peso 2) é um serviço considerado essencial pelo fato da necessidade de atendimento das reservas, ligação para fornecedores e clientes. "Uma vez tivemos problemas com a 
central [telefônica] do hotel. Ficamos dois dias sem poder receber ou realizar ligações. A central queimou. Ficamos "ilhados". O nível de insatisfação subiu neste período. Os hospedes reclamaram muito", afirmou o entrevistado.

Figura 3 - Representação esquemática da cadeia de suprimentos de $1^{\circ}$ nível de serviços.

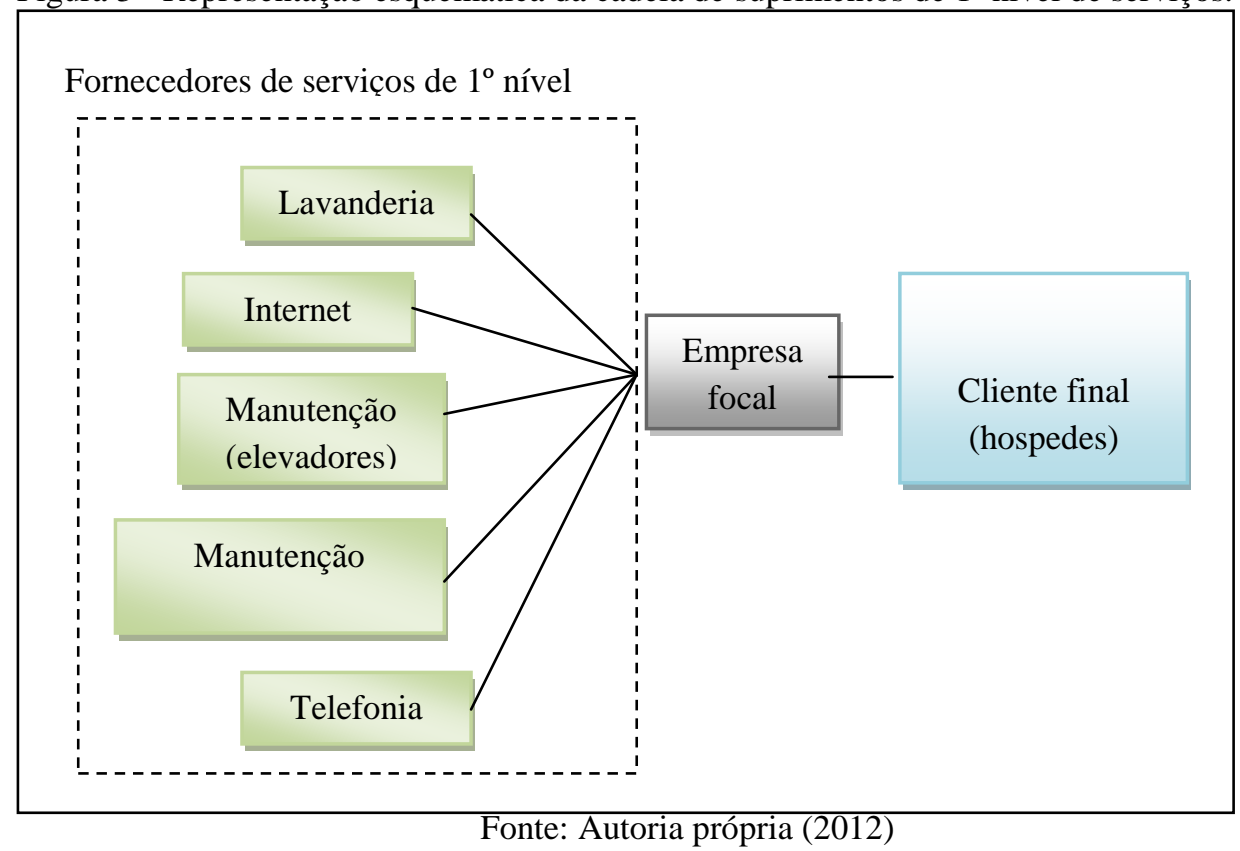

Outro ponto comentado durante a entrevista foi: “A manutenção do ar condicionado é uma operação essencial para o hotel e de difícil realização, pelo fato do hotel ter ar condicionado central. Somos dependentes desta prestação do serviço. O nosso contrato prevê a realização de manutenção [limpeza e regulagem do equipamento] pelo menos três vezes por mês. A temperatura do ar condiciona é a mesma para todos os apartamentos. De vez em quando nossos clientes preferem a temperatura mais alta. Em outras, mais baixa. Por este motivo, o peso atribuído para este elemento é 2 [maior grau de dependência]", afirmou o entrevistado.

Para o item "manutenção de elevadores", o peso atribuído foi 3 (neutro). A justificativa para esta pontuação foi a seguinte: "Não temos problemas com a manutenção de elevadores. Quando precisamos deste serviço ligamos diretamente para o técnico responsável. Está previsto no contrato que não existe exclusividade [para este item]. Podemos chamar o técnico da [empresa] Atlas [Schindler], Otis [...] não existe preferência. Dentro do elevador já existe o telefone do técnico. Ele chega em 15 minutos. Não podemos deixar o hospede [preso] no elevador [por muito tempo]”.

Pode-se perceber, portanto, que a empresa analisada não apresenta nenhum grau de dominância sobre os serviços obtidos pelos fornecedores de primeiro nível da cadeia de suprimentos da empresa, ou seja, não foi atribuído a nenhum dos cinco principais prestadores de serviços o grau 5 ou 4 de dominância. Isto demonstra a dependência do hotel no que diz respeito aos principais prestadores de serviços. 
Há ausência do grau de dominância em relação aos principais prestadores de serviços demonstra maior dependência (fragilidade) pelo fato da empresa analisada indicar, durante a pesquisa, que: "Todos os cinco principais prestadores de serviços podem ser classificados como essenciais". Esta afirmação indica, teoricamente, o alto poder de barganha de, pelo menos, quatro dos cinco prestadores de serviços (a única exceção pode ser realizada ao peso 3 que indica a neutralidade em relação a manutenção de elevadores), conforme apresentado no Quadro 03.

\subsection{Fatores de relacionamento da cadeia de suprimentos de $1^{\circ}$ nível}

Este tópico tem a finalidade de identificar quais os fatores que possuem maior influência no relacionamento da cadeia de suprimentos de $1^{\circ}$ nível, tanto para fornecedores de produtos quanto para prestadores de serviços. A escala adotada compreendeu os seguintes elementos: totalmente satisfeito (TS); parcialmente satisfeito (PS); sem relação (SR); totalmente insatisfeito (TI); e parcialmente insatisfeito (PI).

De acordo com a entrevista realizada, os itens assinalados como totalmente satisfeito foram: i) nível de relacionamento com os fornecedores; ii) realização de parcerias conjuntamente (divulgação de produtos e/ou serviços) visando a comercialização; iii) nível de comunicação com os fornecedores; e iv) qualidade da prestação dos serviços oferecidos pelos fornecedores.

A realização de parcerias conjuntamente entre o hotel e fornecedores deve-se ao fato da inserção de alguns fornecedores (principalmente as vinícolas) expondo produtos, como por exemplo, vinhos, sucos, cremes e hidratantes a base de uva etc. Outros produtos/serviços são oferecidos no hotel em parcerias com empresas da região (chocolates, cuia e bomba para chimarrão, agências de viagem, locadoras de veículos etc.). O objetivo de realizar parcerias com as empresas locais (da Serra Gaúcha) é oferecer produtos/serviços de forma ágil e com praticidade aos clientes. Todas as parcerias são realizadas devido a sugestões realizadas pelos clientes em pesquisas realizadas pelo hotel.

O nível de relacionamento com os fornecedores de $1^{\circ}$ nível da cadeia de suprimento foi considerado, pelo hotel, como "totalmente satisfeito". Acredita-se que o ótimo nível de relacionamento esteja associado ao alto grau de dependência e essencialidade dos produtos/serviços obtidos pelo hotel junto a seus fornecedores.

O alto grau de dependência permite, também, estabelecer um bom nível de confiança com os fornecedores (considerado pela pesquisa como sendo "parcialmente satisfeito"). Esta parcialidade de satisfação quanto ao nível de confiança, faz com que o hotel estabeleça contato com novos fornecedores e prestadores de serviços (parcialmente satisfeito). Outra conclusão estabelecida pode ser atribuída à tentativa do hotel de identificar novos fornecedores com grau de padronização, 
satisfação e qualidade, tendo em vista minimizar o alto grau de dependência dos atuais fornecedores de produtos/serviços.

A busca permanente pela qualidade dos serviços pelo hotel, junto a seus fornecedores, pode ser percebida no item "qualidade na prestação dos serviços oferecidos pelos fornecedores" que obteve resposta "totalmente satisfeita". Este fato está relacionado com a política de qualidade adotada pelo hotel, buscando sempre surpreender os clientes com uma excelente qualidade da prestação de serviços.

O grau de cooperação estratégica entre o hotel e seus fornecedores foi avaliado como “parcialmente satisfeito". Esta cooperação existe com base em negociação com os fornecedores. Os contratos estabelecidos, em regra, são firmados pelo prazo de um ano (curto prazo) com possibilidade de renovação automática (caso não haja discordância de nenhuma das partes).

O poder de barganha também foi considerado "parcialmente satisfeito" pelo hotel. Esta parcialidade pode ser justificada pela redução do poder de negociação com alguns fornecedores (produtos de limpeza/higiene; telefonia; e internet, por exemplo). Esta negociação é realizada pela unidade central estabelecida na cidade de São Paulo, reduzindo o grau de tomada de decisão do hotel junto a alguns fornecedores. Esta "centralização parcial" ocorre pelo fato do hotel uma franquia, podendo a unidade central estabelecer a negociação diretamente com os fabricantes de produtos, assim como avaliando o grau de qualidade dos produtos/serviços oferecidos aos hotéis da rede.

Outro item avaliado como "parcialmente satisfeito" foi à comunicação estabelecida através de sistema de informação compartilhado. Existe integração do sistema do hotel com a unidade central de São Paulo. É através do sistema que existem as solicitações de compras para produtos de limpeza/higiene. A comunicação com os fornecedores de $1^{\circ}$ nível da cadeia de suprimento (exceto o destacado acima) não são realizados pelo sistema, mas sim diretamente (por telefone ou e-mail), pelo fato da contratação dos produtos/serviços ser de empresas locais (da Serra Gaúcha).

\section{Considerações finais}

Esta pesquisa teve como objetivo principal analisar a relação de dominância e dependência exercida em uma cadeia de suprimentos de primeiro nível. Para isto, foram analisados os cinco principais fornecedores de produtos/serviço de primeiro nível da cadeia de suprimentos do hotel (empresa focal do estudo).

Foram realizadas pesquisas junto às principais publicações que dizem respeito à cadeia de suprimentos, nível de poder na cadeia (relação de dominância e dependência), qualidade da prestação de serviços aos clientes e cooperação entre os elementos da cadeia de suprimentos. 
Com base no estudo realizado, pode-se concluir que existe um alto grau de dependência do hotel junto a seus principais fornecedores de produtos e prestadores de serviços, ou seja, a dominância é exercida pelo fornecedor, e não pela empresa pesquisada, conforme afirmam Cox, Sanderson e Watson (2001). Este fato corrobora com os ensinamentos de Svensson (2003) e McIvor (2003), onde evidenciam que a redução do número de empresas participantes da cadeia de suprimentos aumenta o grau de dependência da empresa focal em relação aos fornecedores de produtos e serviços.

O que agrava a dependência são todos os serviços terem sido considerados essenciais pelo entrevistado. Este fato evidencia o alto grau de interdependência entre as empresas envolvidas quanto a prestação de serviços (CASCIARO; PISKORSKI, 2005). Já para os produtos, apenas três dos cinco fornecedores analisados foram considerados essenciais (padaria, produtos de limpeza/higiene e Hortifrutigranjeiro). Os demais elementos (vinícolas e impressos) foram avaliados como não essenciais pelo hotel.

A relação de cooperação entre o hotel e seus fornecedores de primeiro nível é realizada por meio de negociação/parceria, que por sua vez é de curto prazo (até um ano), podendo ser renovado por igual período, a depender do grau de satisfação dos envolvidos.

O hotel busca escolher seus fornecedores de primeiro nível de acordo com o posicionamento geográfico das empresas (localização), conforme estudo de Vivaldini e Pires (2011). Este é um critério é desenvolvido para grande parte dos produtos/serviços. A única exceção é para a prestação de serviços de manutenção dos elevadores (livre escolha entre as empresas que fornecem o serviço).

O tema investigado não foi esgotado totalmente, existindo, portanto, diversas oportunidades para desenvolvimento de estudos futuros. Algumas recomendações que podem ser realizadas para complementação deste estudo são: realizar análise dos demais níveis de fornecedores e/ou clientes do hotel, (fornecedores de terceiro e segundo nível, por exemplo), assim como do nível (grau) de satisfação dos clientes com a prestação dos serviços oferecidos. Realizar um estudo de multiplos casos entre dois ou mais hotéis, passando a relacionar os resultados das entrevistas entre o Sindicato de Hotéis, Restaurantes, Bares e Similares (SHRBS), tendo em vista maior profundidade de análise. Outra oportunidade de estudo futuro é analisar a existência de comportamento oportunista entre fornecedor-comprador dos elementos da cadeia de suprimentos de um hotel.

\begin{abstract}
This article aims to analyze the relationship of dominance and dependence on a first-level supply chain in a hotel of economic segment located in Caxias do Sul (RS). The search can be characterized as being an exploratory qualitative case study. A semi-structured interview was held with the General Manager of the unit, for the purpose of obtaining information needed for the search. The elements analyzed were: relationship of dominance and
\end{abstract}


dependence of the first-level supply chain; quality of service provision; level of essentiality of products and services; and cooperation in the supply chain. The results showed the degree of dependence on suppliers of hotel front five products and services, as well as the low level of cooperation between the participants of the process (short-term contracts based more on the survival of its operations than in obtaining long-term financial return).

Key-word: supply chain; dominance and dependence; serra gaúcha.

\section{Referências}

BARDIN, L. Análise de conteúdo. Lisboa: Edições 70, 1979.

BARRATT, MARK. Understanding the meaning of collaboration in the supply chain. Supply Chain Management: An International Journal, v. 9, n. 1, p.30-42, 2004. crossref

BOWERSOX, D.; CLOSS, D. Logística empresarial: o processo de integração da cadeia de suprimentos. São Paulo: Atlas, 2001.

BOWERSOX, D. J; CLOSS, David J; STANK, Theodore P. How to master cross-enterprise collaboration. Supply Chain Management Review, Jul/Aug 2003.

CAVAllARI, V. C.; SCHWABE, M. G. A.; MACHADO, M. C. Os reflexos da gestão do relacionamento com o fornecedor (SRM) na cadeia de suprimentos de uma indústria de bens de consumo, XIX Simpósio de Engenharia de Produção, 2012, Bauru. Anais..., Bauru, SP, 2012.

CASCIARO, T.; PISKORSKI, M. J. Power imbalance mutual dependence and constraint absorption: A closer look at resource dependence theory. Administrative Science Quarterly, v. 50, n. 2, p. 167-199, june, 2005.

CHOPRA, S.; MEINTL, P. Gestão da Cadeia de Suprimentos: Estratégia, Planejamento e Operações. São Paulo: Pearson Prentice Hall, 2001.

CHRISTOPHER, Martin. Logística e gerenciamento da cadeia de suprimentos. São Paulo: Cengage Learning, 2012.

COUGHLAN, A. T.; ANDERSON, E.; STERN, L. W.; EL-ANSARY, A. I. Canais de marketing e distribuição. Porto Alegre: Bookman, 2002.

COX, A. Power, value and supply chain management. Supply Chain Management: An International Journal, v. 4, n. 4, p. 167-175, 1999. . The art of the possible: Relationship management in power regimes and supply chain. Supply Chain Management: An International Journal, v. 9, n. 5, p.346-356, 2004. crossref

COX, A.; SANDERSON, J.; WATSON, G. Supply chains and power regimes: toward an analytic framework for managing extended networks of buyer and supplier relationships. The Journal of Supply Chain Management, v. 37 , n. 2, p. 28-35, March, 2001. crossref

EISENHARDT, K. M. The Qualitative Researcher's Companion Building Theories From Case Study Research. In: A. M. Huberman; M. B. Miles (Eds.). The Qualitative Researchers Companion, p.1-16, 2010.

FABBE-COSTES, N.; JAHRE, M.; ROUSSAT, C. Supply chain integration: the role of logistics service providers. International Journal of Produtivity and Performance Management, v. 58 n. 1, p. 71-91, 2009.

GILLEY, K. M.; RASHEED, A. Making more by doing less: An analysis of outsourcing and its effects on firm performance. Journal of Management, v. 26 n. 4, p. 763-790, 2000. crossref

GULATI, R.; SYTCH, M. Dependence asymmetry and joint dependence in interorganizational relationships: Effects of embeddedness on a manufacturer's performance in procurement relationships. Administrative Science Quarterly, v. 52, n. 1, p. 32-69, march, 2007. 
HARLAND, C.; KNIGHT, L.; LAMMING, R.; WALKER, H. Outsourcing: assessing the risks and benefits for organisations, sectors and nations, International Journal of Operations \& Production Management, v. 25 n. 9 , p.831-850, 2005. crossref

LAKATOS, E. M. MARCONI, M. de A. Técnicas de pesquisa: planejamento e execução de pesquisa, amostragens e técnicas de pesquisa, elaboração, análise e interpretação de dados. 7 ed. São Paulo: Atlas, 2011.

LAMBERT, Douglas M.; STOCK, James R. \& VANTINE, José Geraldo. Administração estratégica da logística. São Paulo: Vantine Consultoria, 1996.

LONSDALE, C. Locked-in to supplier dominance. on the dangers of asset specificity for the outsourcing decision. Journal of Supply Chain Management, v. 37, n. 2, p. 22-27, 2001. crossref

MAlHOTRA, N. Pesquisa de marketing: foco na decisão. 3 ed. São Paulo: Pearson Prentice Hall, 2011.

MCIVOR, R. Outsourcing: insights from the Telecommunications Industry. Supply Chain Management: An International Journal, v. 8, n. 4, p. 380-394, 2003. crossref

MiN, S.; ROATH, A. S.; DAUGHERTY, P. J.; GENCHEV, S. E.; CHEN, H.; ARNDT, A. D.; Supply Chain Collaboration: What's happening? The International Journal of Logistics Management, v. 16, n. 2, p. 237-256, 2005. crossref

SVENSSON, G. Sub-contractor and customer sourcing and the occurrence of disturbances in firms inbound and outbound logistics flows. Supply Chain Management: an International Journal, v. 8, n. 1, p. 41-56, 2003. crossref

VIVALDINI, M.; PIRES, S. R. I. Utilização do mesmo prestador de serviços logísticos (PSL) por empresas concorrentes. Revista Gestão Industrial. v. 7, n. 4, p. 30-53, 2011. crossref

YIN, R. K. Estudo de caso: planejamento e métodos. 4 ed. Porto Alegre: Bookman, 2010.

\section{Dados dos autores}

Nome completo: Rodrigo Marques de Almeida Guerra

Filiação institucional: Universidade de Caxias do Sul

Função ou cargo ocupado: Professor e Coordenador do Curso de Administração da UCS

Farroupilha.

Endereço: Rodovia dos Romeiros, 567 - Bela Vista - CEP 95180-000 - Farroupilha - RS

Telefone: (54) 3261-2922

e-mail:rmaguerra@ucs.br

Nome completo: Maria Salete Goulart Martins Denicol

Filiação institucional: Universidade de Caxias do Sul

Função ou cargo ocupado: Professora

Endereço: Campus Universitário de Caxias do Sul - Bloco F. Rua Francisco Getúlio Vargas, 1130 -

CEP 95070-560 - Caxias do Sul - RS

Telefone: (54) 3218-2267

e-mail: msdenicol@gmail.com 
Filiação institucional: Universidade de Caxias do Sul

Função ou cargo ocupado: Professor

Endereço: Campus Universitário de Caxias do Sul - Bloco F. Rua Francisco Getúlio Vargas, 1130 CEP 95070-560 - Caxias do Sul - RS

Telefone: (54) 3218-2011

e-mail: gcmalafa@ucs.br

Nome completo: Vilmar Antônio Gonçalves Tondolo

Filiação institucional: Universidade de Caxias do Sul

Função ou cargo ocupado: Professor

Endereço: Campus Universitário de Caxias do Sul - Bloco F, sala 401 Rua Francisco Getúlio

Vargas, 1130 - CEP 95070-560 - Caxias do Sul - RS

Telefone: (54) 3218-2011

e-mail: vtondolo@gmail.com

Submetido em: 23/08/2013

Aceito em: 11/10/2014 